\title{
Design of eddy current brake for electric motorcycle braking system
}

\author{
Mufti Reza Aulia Putra1, Muhammad Nizam², Dominicus Danardono Dwi Prija Tjahjana ${ }^{3}$ \\ ${ }^{1,3}$ Departement of Mechanical Engineering, Universitas Sebelas Maret, Surakarta, Indonesia \\ ${ }^{2}$ Departement of Electrical Engineering, Universitas Sebelas Maret, Surakarta, Indonesia
}

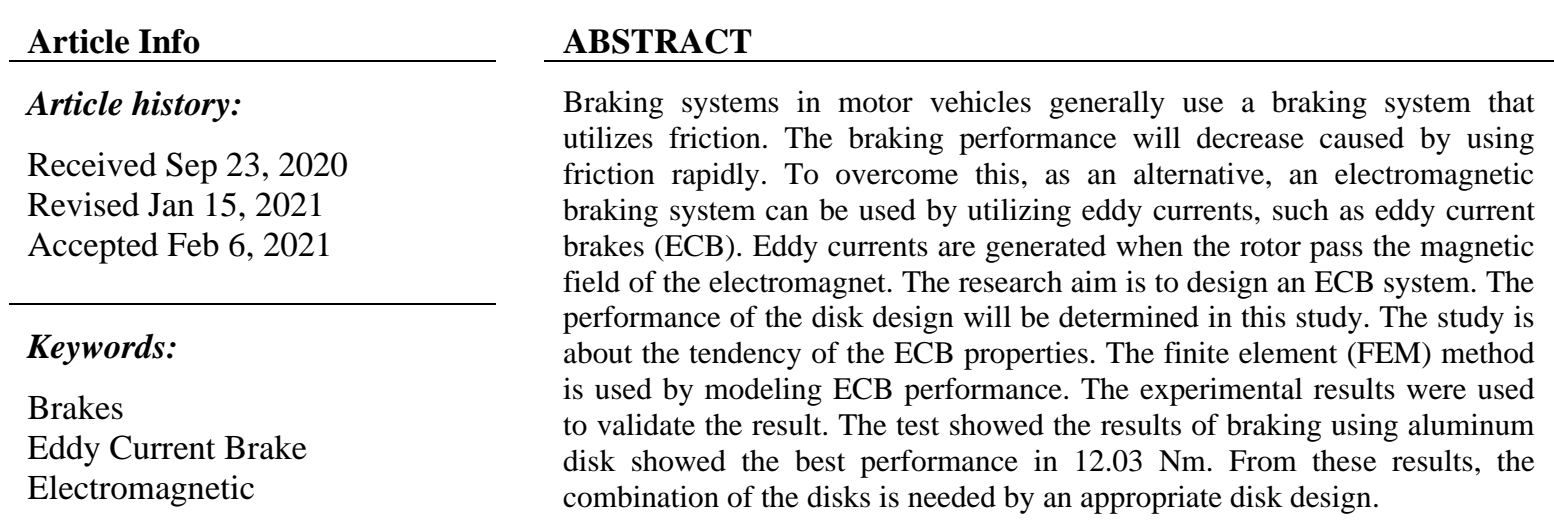

This is an open access article under the $\underline{C C B Y-S A}$ license.

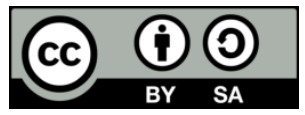

\author{
Corresponding Author: \\ Muhammad Nizam \\ Departement of Electrical Engineering \\ Universitas Sebelas Maret \\ Ir. Sutami No.36A, Kentingan, Jebres, Surakarta, Jawa Tengah 57126, Indonesia \\ Email: muhammad.nizam@staff.uns.ac.id
}

\section{INTRODUCTION}

One part of motorized vehicles that supports driving safety is the brakes. Brake is a tool that serves to reduce or stop the speed of the vehicle. The use of motorized vehicles has dynamic road contours, such as those in hilly and mountainous areas. In these areas, many uphill and derivative roads require the vehicle to have a good braking capability. In another side, better braking performance is important on toll roads where vehicles will operate at high speeds. Repeated braking conditions because the braking performance is not optimal, so it is often the cause of an accident. The development of transportation modes brought changes to the braking system and components. The development of electric vehicles or hybrid vehicles allows the use of electronic devices that have higher energy efficiency. In electric vehicles it is not possible to use engine brakes, the braking component that can be used is regenerative braking. Regenerative braking commonly used as braking with produce electricity capabilities [1], [2]. The electric current produced by regenerative braking can be saved in batteries for other purposes such as an electric braking system. Many researches on electric brakes, eddy current brake (ECB) is one of an electric brake type. The ECB is generally found in heavy vehicles, high-speed vehicles to light vehicles such as motorcycles applications [3], [4]. Eddy currents are generated by induction from a magnetic field that intersects by rotor [5], [6]. The eddy current produced makes a new magnetic field, the magnetic field will interrupt primary magnet formed by the stator coil. This interaction creates a braking force [4].

ECB produces braking with a force that depends on the rotational speed and several parameters [7][9]. There are many types of materials used as conductors in eddy current brakes. One of the best ones is 
using aluminum [8]. One of the better ECB designs is a unipolar design [10]. However, there is very little research on the integration of the ECB braking system. Especially the integration of conventional braking and the ECB. Recent studies have shown the tendency of conductor's properties on braking torque. Therefore, this research will do a construction simulation that aims to find the braking torque of an aluminum ECB conductor by changing the air gap and disk properties.

\section{THEORITICAL}

The use of motorcycle disks as ECB rotors requires a study of several parameters. In ECB braking there are influences of material, disk thickness and air gap used [8], [11]. The material will affect the performance of the ECB, such as the effect of using aluminum or iron material on the ECB disk [5], [12], [13]. In its use ferrous material has an unfavorable performance trend, this is caused by the conductivity value of each material used [14]. The use of ferrous material is not very suitable to use so it needs to be replaced by non-ferro material [5]. The tendency of disk thickness in the ECB braking process is very high. The skin effect will be decreased when using a thick disk [9], [15]. The air gap that is used at the magnetic source will also affect the resulting critical speed [16], [17].

Changes in disk properties result in changes in braking performance. One of the changes made is changing the material used. One of the materials that have the best torque is aluminum. Besides, there is an effect from heat generated [18]. The effect of the temperature will change the critical speed and the torque [19]. In studies that have had a heat that affects the braking process is at high temperatures [20], [21]. There are several things that need to be considered before conducting a simulation, namely the domain, boundary conditions, meshing, and material properties. It is also necessary to understand the governing equation used in the simulation process used. The (1), (2) and (3) are governing equations used in this study [22]. With $\mathrm{E}=$ electric field, $\mathrm{B}=$ flux density, $\mathrm{J}=$ Eddy current density, $\mathrm{F}=$ Braking force and $\mathrm{T}=$ Braking torque.

$$
\begin{aligned}
& \nabla \times \vec{E}=-\frac{\partial \vec{B}}{\partial t} \\
& \vec{F}=\vec{J} \times \vec{B} \\
& \vec{T}=\vec{F} \cdot r
\end{aligned}
$$

Basically, the (1) Faraday's law then in (2) is Gaus' law and (3) is Ampere's law. These equations are the basic equations used in eddy current simulations [23]. ECB is a contactless braking method. The ECB performance provides from a magnetic flux source such as a permanent magnet or an electromagnet. The braking torque of the ECB can also be calculated quite accurately in the low and high-speed range. The resulting braking torque is affected by the electromagnetic field. Braking torque can be determined through the following equation. With $\sigma=$ disk conductivity, $\delta=$ disk thickness $(\mathrm{mm}), \omega=$ rotationa speed $(\mathrm{rpm})$, $\mathrm{r}=$ electromagnet radius, $\mathrm{m}=$ magnet position $(\mathrm{mm}), \mathrm{B}=$ flux density, and $\mathrm{a}=$ disk radius $(\mathrm{mm})$.

$$
\mathrm{T}=\frac{1}{2} \times \sigma \delta \omega \pi r^{2} m^{2} B_{z}^{2}\left[1-\frac{\left(\frac{r}{a}\right)^{2}}{\left(1-\left(\frac{m}{a}\right)^{2}\right)^{2}}\right\}
$$

The (4) shows that the thickness of the disc, angular velocity, electromagnetic radius, axis distance with ECB placement, flux density, and radius will influence the performance of the ECB. In addition, the influence of disk thickness can be seen from (5) [11]. With $\mathrm{t}=$ thickness $(\mathrm{mm}), \mathrm{f}=$ frekuensi $(\mathrm{Hz}), \mu=$ magnetic permeability $(\mathrm{H} / \mathrm{m})$, and $\sigma=$ electrical conductivity $(\mathrm{S} / \mathrm{m})$.

$$
t=\frac{1}{\sqrt{\pi f \sigma \mu}}
$$

\section{METHOD}

This study used the FEM by using an electromagnet and with an aluminum and iron disk rotors. After obtaining stable data, variations in material, air gaps and disk thickness is made. The arrangement of the braking system with the coil conducts electricity from electromagnetism. In the magnetic field will arise eddy current which causes the braking effect, this braking will be analyzed the results. The simulation process is carried out using material changes. The first material used was iron because motorcycle disks generally used iron material and used disks with aluminum material to replace the disk material. Figure 1 
shows the method of this research. In addition to material variations, variations in the air gap and variations in disk thickness will be made at the same winding-core size. Next, perform braking performance on the disk by looking at the torque produced. In the air gap test, it is noted that the coil core has a different size while the variation in disk thickness used uses the same coil core size. Tests carried out by performing simulations using 360 turns and using a current of 20A. Tests carried out using a rotating speed that varies at 150, 300, 450, 600 and $750 \mathrm{rpm}$. The results of the study conducted validation on the data obtained by conducting experiments. The experiment was conducted to compare the experimental data with the simulations that have been carried out.

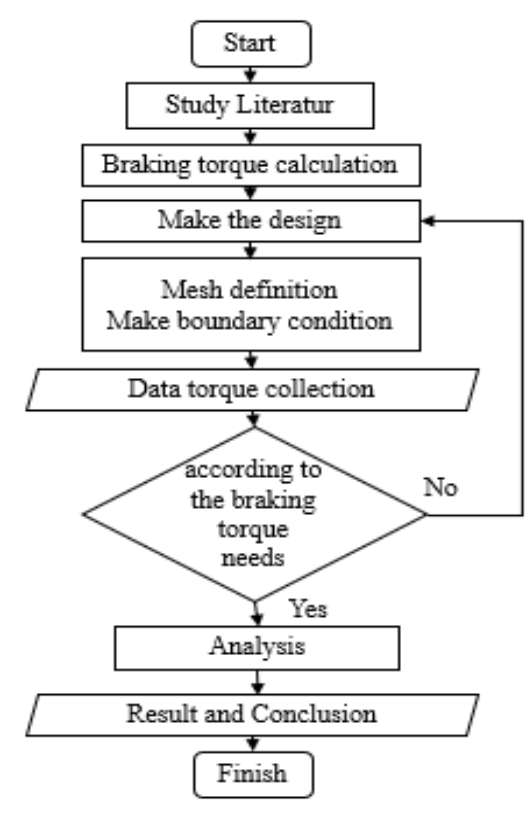

Figure 1. The process of the research

\section{EXPERIMENTAL PROCESS}

In this study, an experimental process aims to validate the model. The experimental set up is shown in Figure 2. Figure 2 and Figure 3 shows that ICE is used to rotate the disk, use a constant angular velocity. Then the electromagnet functions as a supplier of magnetic flux that penetrates the polar projection area in the disc $[24,25]$. The reaction torque generated during the braking process is translated using a load cell. Experiments carried out using 20A current and 12V voltage using 360 turns. These settings are adjusted to the simulation process that has been carried out.
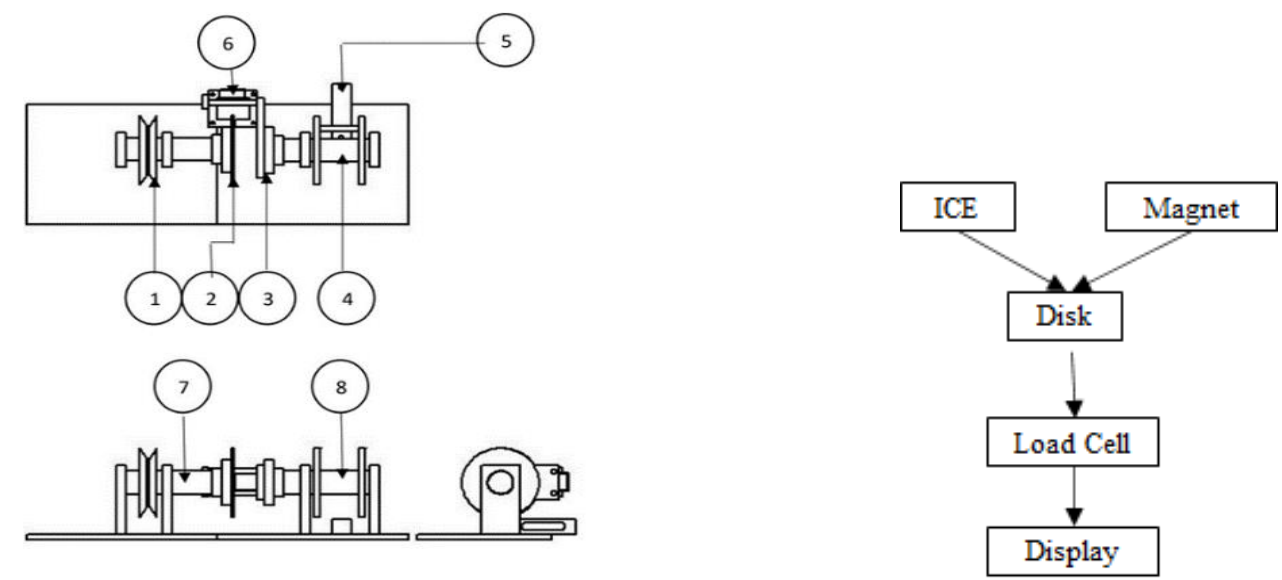

Figure 2. Experimental design 1) pulley, 2) disk, 3) bracket, 4) stopper, 5) load cell, 6) electromagnet, 7) power, and 8) magnet.

Figure 3. Eksperimental setup 


\section{RESULT}

The braking process will be collected by the simulation process. The characteristics of the influence of the air gap will be shown from the simulation process. The model used in this process such as conventional disk brakes principles. The testing process is done by transient simulation using the time domain, 360 turns and using a current of 20 A. Tests carried out using a rotating speed that varies at 150, 300, 450, 600 and $750 \mathrm{rpm}$. No heat losses are generated. To find out the results of the simulation in accordance with the real results or not validated from the simulation process used. One way is to change the settings used in the simulation process in the form of mesh used. In this process 4 different kinds of mesh changes were used, namely $5 \mathrm{~mm}, 10 \mathrm{~mm}, 15 \mathrm{~mm}$ and $20 \mathrm{~mm}$. The mesh in question is the nodal size used on the surface of the model to be used as in Figure 4.

From Table 1, a smaller value of the mesh used makes the data from the simulation process more stableThe value that is indicated by the results of the change in value in the table that shows the results of changes in the performance that results.

Based on Table 1 it is known that the smaller the mesh value used can increase the maximum torque produced. The maximum torque produced has increased to a size of $10 \mathrm{~mm}$, but the change in yield value between $10 \mathrm{~mm}$ and $5 \mathrm{~mm}$ has a relatively small difference in value. Therefore, the mesh value used is $5 \mathrm{~mm}$, this is because at that value the maximum torque change produced is quite small but has a smaller data deviation value so that it can describe the actual results. Flux distribution when braking as shown in Figure 5.

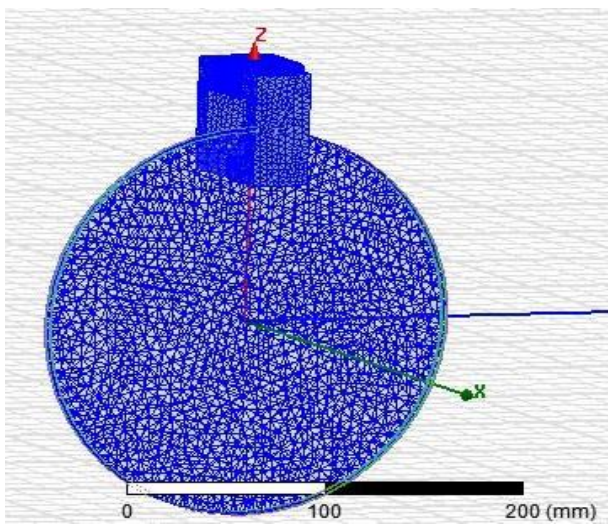

Table 1. Self validation process

\begin{tabular}{ccc}
\hline $\operatorname{Mesh}(\mathrm{mm})$ & Torque $(\mathrm{Nm})$ & Error \\
\hline 5 & 9.43 & $2 \%$ \\
10 & 9.42 & $8.5 \%$ \\
15 & 4.15 & $22 \%$ \\
20 & 4.02 & $26.5 \%$ \\
\hline
\end{tabular}

Figure 4. Meshing FEM

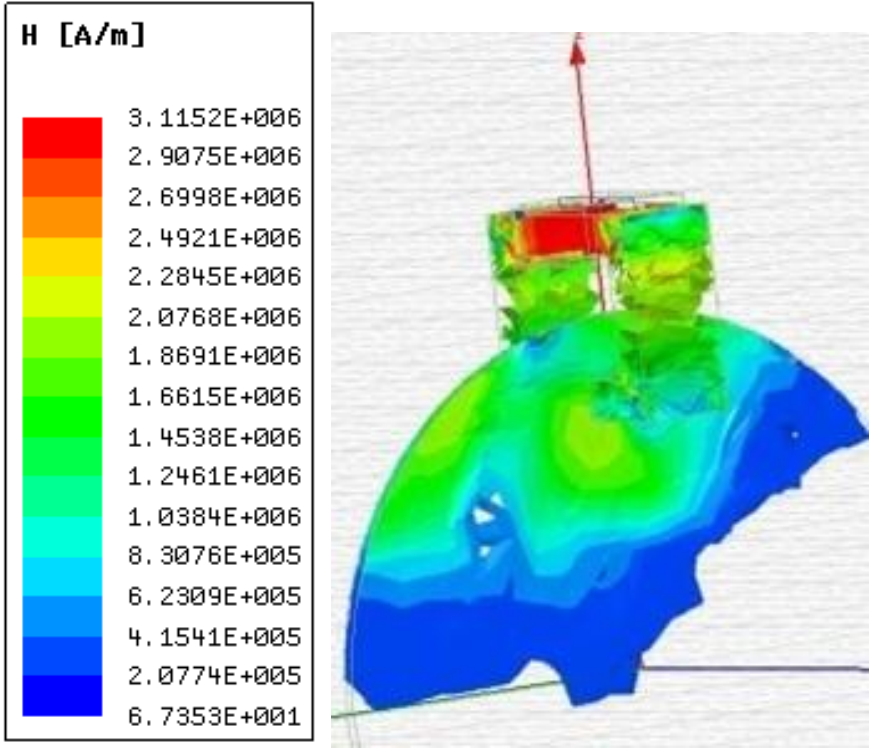

Figure 5. Flux distribution when braking 
After the validation process, the simulation process is carried out variations using different materials. The material used is aluminum and iron. This is because in general, existing vehicles use iron disks, while the appropriate material is non-ferrous material, which is represented by aluminum. This test conducted with the same coil core size.

\section{Braking Performance}

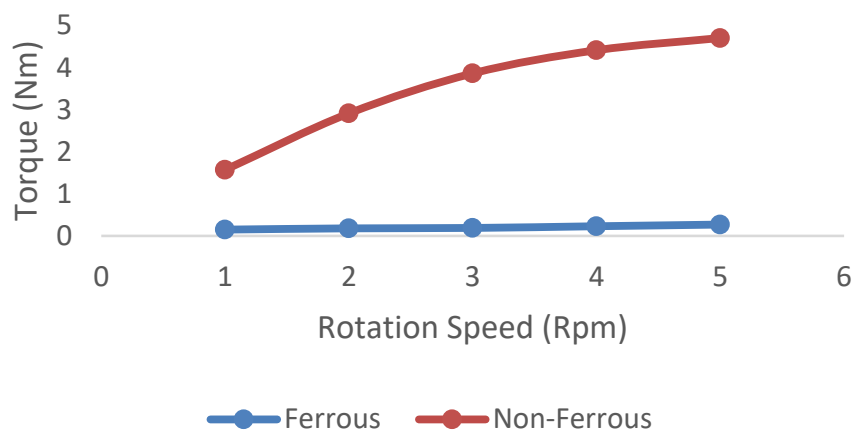

Figure 6. Braking torque on material change

The variation of material used shows that aluminum material has a better performance compared to iron. This is caused by the nature of the aluminum material which is a non-ferrous material which can be seen in Figure 6. Besides the use of aluminum is also better because it can release a magnetic field that is better than iron. The use of iron material in the conductor also affects the results of braking torque, because iron has high permeability properties so that it can help strengthen the concentration of eddy currents formed in the conductor. A higher of the conductivity value will increase the torque generated by the ECB. Because of the formula for calculating the conductivity value is directly proportional to the braking torque. The material that is quite good to use is aluminum material with a conductivity value of $3.5 \times 10^{\wedge} 7 \mathrm{~S}$, while to get good braking performance, it can be done with materials with conductivity values between $5 \times 10^{\wedge} 6 \mathrm{~S}$ to $3.5 \times 10$ $\wedge 7 \mathrm{~S}$. In aluminum material, the graph produced has a different trend with iron, namely high braking torque at low speeds compared to using iron material because the material is non-ferrous, in a study conducted by Lequesne [26], showing the characteristics of ECB braking using material non-Ferro and Ferro. In optimal conditions, it has an average braking torque below $16 \mathrm{Nm}$. This is due to the lower conductivity of aluminum compared to iron. Another effect is Critical speed on different aluminum. The next process is the simulation by varying the thickness of the disk. This is done because an analysis of the effect of the thickness of the disk on the torque produced is needed. By using the same winding-core size.

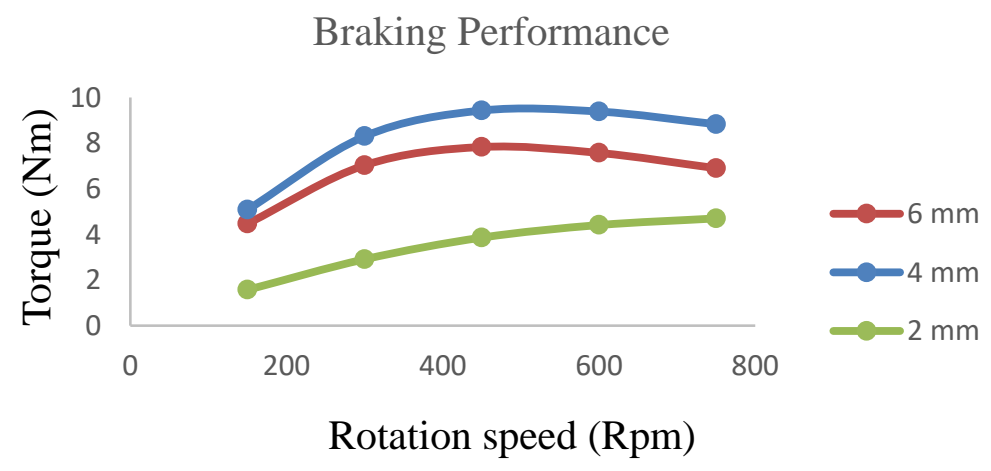

Figure 7. Torque on disk thickness change 
As seen in Figure 7 it is known that braking by using disk size changes shows that the smaller the thickness of the disk used will result in a decrease in braking performance. Braking used shows that the need to separate the ECB disk with conventional brakes because the thickness of the disk will affect the performance of the ECB. This is caused when the thinner the disk will reduce the value of the eddy current generated. Whereas when it gets thicker it will cause obstacles from the currents that arise even greater. In the variation of air gap which is done using aluminum, the material shows the results like a graph.

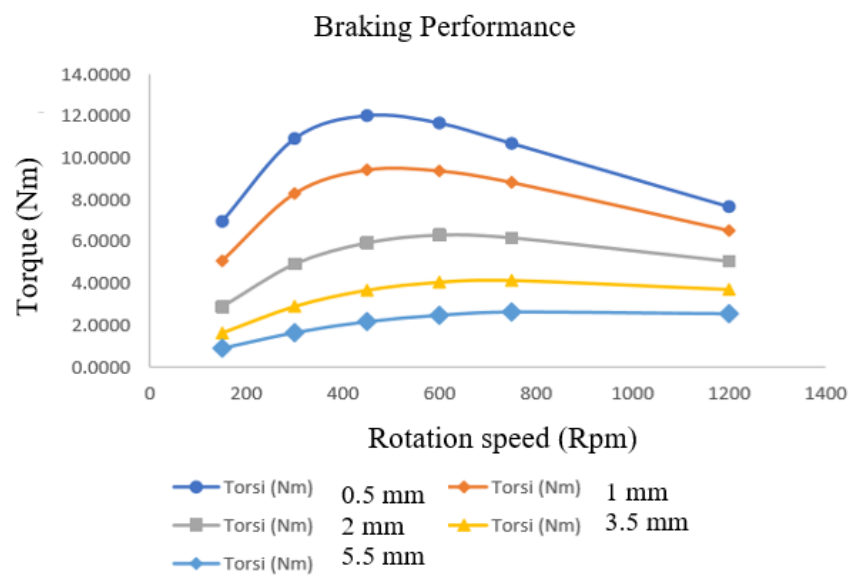

Figure 8. Air gap change

The increase in torque. The increase of the torque will stop after reaching the critical speed. The critical speed characteristics of the ECB depend on the conductor material used. The skin effect is a highfrequency magnetic flux in the conductor resulting in eddy currents that arise will thin or appear on the surface of the conductor so that the resulting braking torque will decrease Critical speed is caused by the skin effect. Figure 8 shows that a smaller air gap increases the braking torque. This is caused by using non-Ferro conductor material, which will produce a parabolic graph. The results will rise with increasing speed until it reaches a critical speed. After reaching the critical speed braking will tend to go down. The critical speed shown is seen from the data trends shown on the graph by providing additional speed values at $1200 \mathrm{rpm}$. It aims to see the characteristics of the ECB where changes in the gap used will result in a shift in the location of the critical speed. Based on the simulation process that has been carried out it can be seen that the simulation process that has been carried out has a trend that is by previous research. Previous studies have shown that the trends shown are under the characteristics of the ECB. To find out whether the data obtained from the simulation process is valid or not, it is necessary to verify the data. The data verification process is carried out by conducting an experimental process.

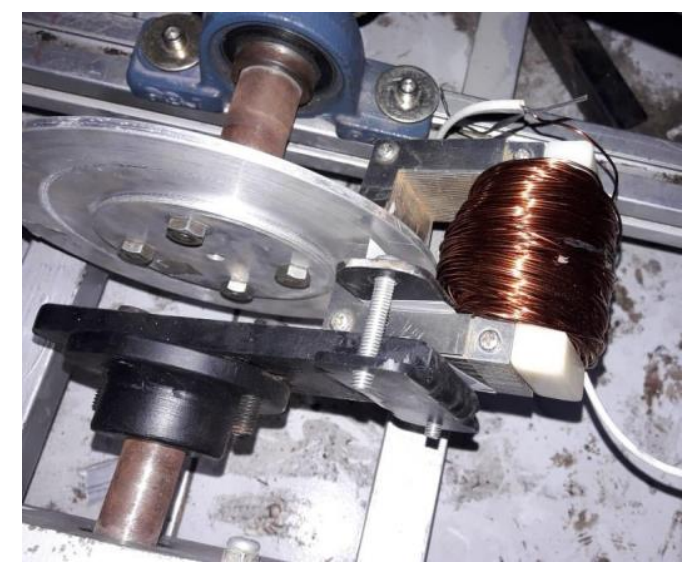

Figure 9. Experimental parts 
From the experimental process, the results of the comparison between the torque of the simulation results and the torque from the experiments shown in Figure 9.

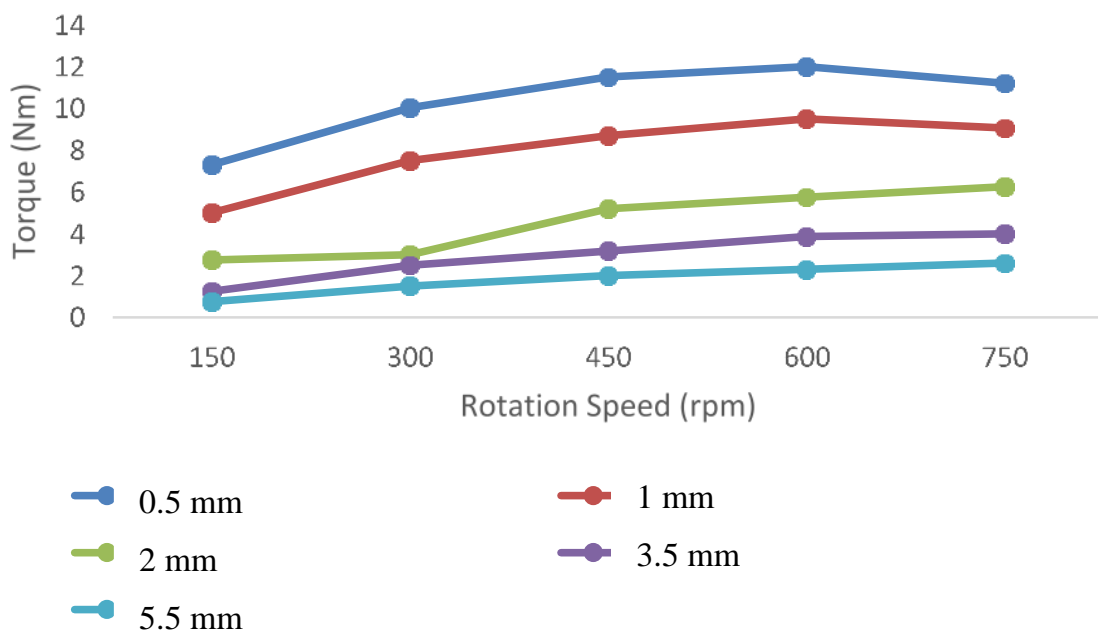

Figure 10. Braking torque with changes in air gap using an experimental process

From Figure 10 it is known that there is a difference in the trend in the braking graph in the experimental process with the rotating speed applied. The difference can be seen in the $0.5 \mathrm{~mm}$ gap where there is a significant change when there is a change in rotational speed, whereas when the gap used is changed, it causes smaller data changes. The difference in the trend that occurs in the results of the sensing is due to the phenomenon of skin effect, which means that the magnetic field current density varies in the conductor based on the air gap on the conductor's surface. In the comparison data between the experimental data and the simulation data that has been shown in Figure 8, it can be seen that there are differences in graphic trends in the experimental and simulation data.

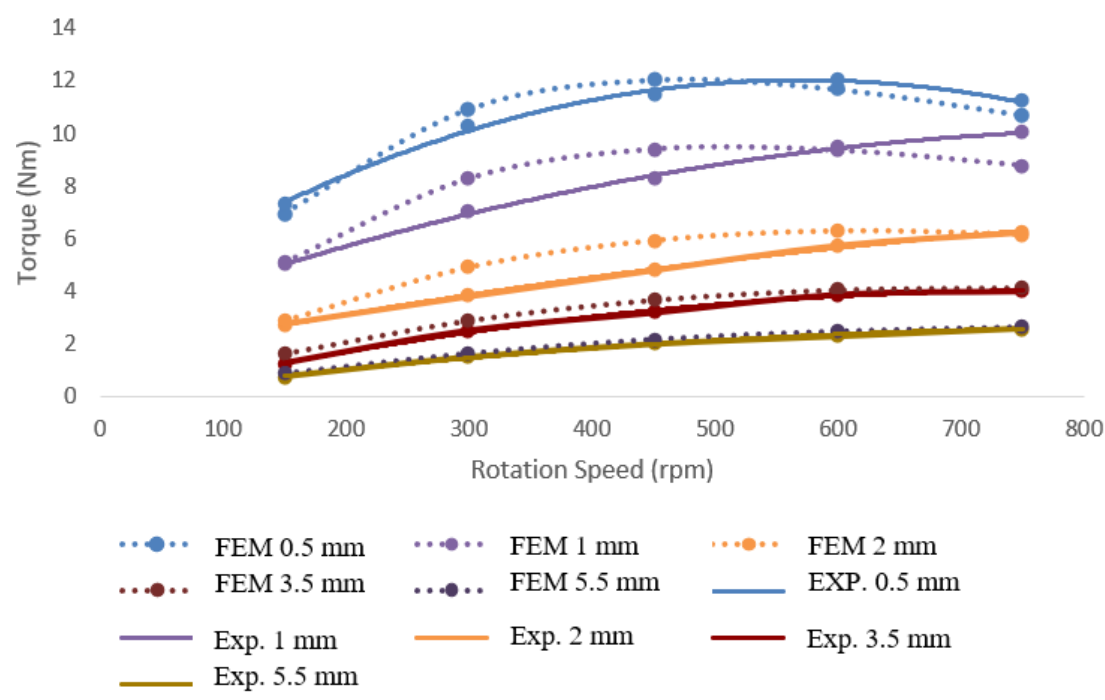

Figure 11. Comparison of braking torque between experimental and simulation processes

In the gap data $0.5,1,2,3.5$ and $5.5 \mathrm{~mm}$, at this gap, the critical speed point has been exceeded causing the braking torque to decrease in accordance with the characteristics of the ECB that uses aluminum as the conductor material shown by Figure 11. However, there is a large difference in torque braking that 
arises in the process of experimentation and simulation is influenced by several factors, namely the occurrence of vibrations in the engine stand during the data collection process caused by ICE so that it affects the reading of data in the load cell, besides the occurrence of heat in the windings, as well as the use of iron material used as an electromagnetic bracket affects the performance of the ECB. In addition to the above, the influence of heat that arises during the braking process also affects the torque produced even though the effect is quite small. In existing research, the braking process can be influenced by temperature. Other factors that cause differences that occur are also caused by the normal forces that arise and affect the conductor, so that friction occurs between the conductor and the electromagnet.

In the results of $2 \mathrm{~mm}$ gap braking torque data, the large difference in braking torque created in the experimental and simulation processes is influenced by the presence of vibrations during the testing process, causing vibrations on the engine stand and affecting the reading of the load cell, another thing that causes a large difference in braking torque namely the generation of heat in the windings, as well as the use of iron material used as an electromagnetic bracket, affects the braking performance produced from the ECB. In addition to some of the above, the influence of heat that arises during the braking process also affects the torque produced although the effect is can be ignored.

Table 2. Torque comparisson

\begin{tabular}{cccc}
\hline \multirow{2}{*}{ Speed (rpm) } & \multicolumn{2}{c}{ Torque $(\mathrm{Nm})$} & \multirow{2}{*}{ error\% } \\
& Experimen & FEM & \\
\hline 150 & 7.3 & 6.97 & $4, .52$ \\
300 & 10.3 & 10.92 & 6.01 \\
450 & 11.5 & 12.03 & 4.6 \\
600 & 12 & 11.67 & 2.75 \\
750 & 11.2 & 10.69 & 4.5 \\
& Mean (\%) & & 4.476 \\
\hline
\end{tabular}

In Table 2 it can be seen that the average value of errors obtained based on the comparison between the results of experiments with simulations that have been carried out is quite small. The magnitude of the error value arising from the difference in the value of the braking torque created between experiments and simulations is influenced by the influence of the high winding temperature and the heat during the braking process that affects the braking torque that arises, besides that it is quite difficult to maintain the rotational speed at the ICE, so affect the results of braking torque, and also the emergence of vibrations that affect readings in the load cell, as well as the influence of the material used for the brackets used in the electromagnet. By looking at the error value generated below 5\% so that it can be stated that the resulting data is valid.

Based on the testing and simulation process carried out it is known that the highest torque value is obtained at $12 \mathrm{Nm}$. In actual use, the braking process requires consideration of the braking torque needed in a process of reducing vehicle speed. In this case, the braking torque calculation is performed when the slowing process is carried out from $60 \mathrm{~km} / \mathrm{h}$ to $20 \mathrm{~km} / \mathrm{hr}$ which is $26 \mathrm{Nm}$. Uses the calculation of the energy needed for a $100 \mathrm{~kg}$ vehicle. So that the use of ECB can reduce $46 \%$ of the braking torque requirements required by the braking system. In the process of ECB utilization, braking performance can still be improved, such as using a larger current and number of turns. This will increase the braking torque produced.

\section{CONCLUSION}

The result shows that a smaller air gap will increase braking torque. This provides an overview of the effects of design changes that are given. In studies that have been carried out using changes in material type, disk thickness and air gap used it is known that the material from a disk in the form of iron is not suitable as a ECB disk so it is necessary to use aluminum material as an ECB disk or it can be done by combining the two types of material. The smaller the disk thickness will reduce the braking performance of the ECB. The best braking torque produced is using aluminum material using a $0.5 \mathrm{~mm}$ air gap with a $4 \mathrm{~mm}$ disk thickness of $12.03 \mathrm{Nm}$.

\section{ACKNOWLEDGEMENTS}

This work was funded by the Ministry of Research, Technology (KEMRISTEK/BRIN) of the Republic of Indonesia, through contract no. 208/SP2H/LT/DPRM/2020. 


\section{REFERENCES}

[1] M. Nizam, A. Mohamed, and A. Hussain, "Dynamic voltage collapse prediction on a practical power system using power transfer stability index," 2007 5th Student Conf. Res. Dev. SCORED, no. December, pp. 0-5, 2007.

[2] W. Sutopo, R. W. Astuti, A. Purwanto, and M. Nizam, "Commercialization model of new technology lithium ion battery: A case study for smart electrical vehicle," Proc. 2013 Jt. Int. Conf. Rural Inf. Commun. Technol. Electr. Technol. rICT ICEV-T 2013, 2013.

[3] J. N. Bae, Y. E. Kim, Y. W. Son, H. S. Moon, C. H. Yoo, and J. Lee, "Self-Excited Induction Generator as an Auxiliary Brake for Heavy Vehicles and Its Analog Controller," IEEE Trans. Ind. Electron., vol. 62, no. 5, pp. 3091-3100, 2015.

[4] O. Rodrigues, O. Taskar, S. Sawardekar, H. Clemente, and G. Dalvi, "Design \& Fabrication of Eddy Current Braking System," Int. Res. J. Eng. Technol., vol. 03, no. 04, pp. 809-815, 2016.

[5] J. H. Wouterse, "Critical torque and speed of eddy current brake with widely separated soft iron poles," IEE Proc. B Electr. Power Appl., vol. 138, no. 4, pp. 153-158, 1991.

[6] S. Cho, H. C. Liu, H. Ahn, J. Lee, and H. W. Lee, "Eddy Current Brake with a Two-Layer Structure: Calculation and Characterization of Braking Performance," IEEE Trans. Magn., vol. 53, no. 11, 2017.

[7] M. O. Gulbahce, D. A. Kocabas, and A. K. Atalay, "Determination of the effect of conductive disk thickness on braking torque for a low power eddy current brake," Int. Conf. Power Eng. Energy Electr. Drives, no. May, pp. 1272-1276, 2013.

[8] K. Karakoc, E. J. Park, and A. Suleman, "Improved braking torque generation capacity of an eddy current brake with time varying magnetic fields: A numerical study," Finite Elem. Anal. Des., vol. 59, pp. 66-75, 2012.

[9] A. Sinmaz, M. O. Gulbahce, and D. A. Kocabas, "Design and finite element analysis of a radial-flux salient-pole eddy current brake," ELECO 2015 - 9th Int. Conf. Electr. Electron. Eng., no. 1, pp. 590-594, 2016.

[10] H. T. Waloyo, D. D. D. P. Tjahjana, M. Nizam, and T. Koga, "Mini review on the design of axial type eddy current braking technology," vol. 10, no. 4, pp. 2198-2205, 2019.

[11] G. L. Anantha Krishna and K. M. Sathish Kumar, "Experimental Investigation of Influence of Various Parameters on Permanent Magnet Eddy Current Braking System,” Mater. Today Proc., vol. 5, no. 1, pp. 2575-2581, 2018.

[12] B. Kou, Y. Jin, H. Zhang, L. Zhang, and H. Zhang, "Modeling and analysis of force characteristics for hybrid excitation linear eddy current brake," IEEE Trans. Magn., vol. 50, no. 11, 2014.

[13] M. Z. Baharom, "Electromagnetic Braking System Using Eddy Current for Brake Disc of Al6061 and A17075," no. December 2014, 2012.

[14] M.R.A Putra, M. Nizam, and D.D.P. Tjahjana "Design Study in Single Disk Axial Eddy Current Brake," Proceeding - 2018 5th Int. Conf. Electr. Veh. Technol. ICEVT 2018, pp. 158-160, 2019.

[15] R. K. Srivastava and S. Kumar, "An alternative approach for calculation of braking force of an eddy-current brake,” IEEE Trans. Magn., vol. 45, no. 1, pp. 150-154, 2009.

[16] M. Gulec, E. Yolacan, and M. Aydin, "Design, analysis and real time dynamic torque control of single-rotorsingle-stator axial flux eddy current brake," IET Electr. Power Appl., vol. 10, no. 9, pp. 869-876, 2016.

[17] E. Simeu and D. Georges, "Modeling and control of an eddy current brake," Control Eng. Pract., vol. 4, no. 1, pp. 19-26, 1996.

[18] Y. Jin, B. Kou, L. Zhang, H. Zhang, and H. Zhang, "Magnetic and thermal analysis of a Halbach Permanent Magnet eddy current brake," 19th Int. Conf. Electr. Mach. Syst. ICEMS 2016, pp. 5-8, 2017.

[19] W. Xu and D. Wang, "Calculation of eddy current loss and thermal analysis for adjustable permanent magnetic coupler," Proc. 2011 Int. Conf. Electron. Mech. Eng. Inf. Technol. EMEIT 2011, vol. 9, pp. 4405-4408, 2011.

[20] Y. Ji, J. Wang, Y. Xu, Z. Liu, Y. Zhou, and J. Li, "Study on the Thermal-Magnetic Coupling Characteristics of Integrated Eddy Current Retarder," 2018.

[21] X. Lu, Y. Li, M. Wu, J. Zuo, and W. Hu, "Rail temperature rise characteristics caused by linear eddy current brake of high-speed train," J. Traffic Transp. Eng. (English Ed., vol. 1, no. 6, pp. 448-456, 2014.

[22] K. J. Bathe, H. Zhang, and Y. Yan, "The solution of Maxwell's equations in multiphysics," Comput. Struct., vol. 132, pp. 99-112, 2014.

[23] ANSYS, “ANSYS Maxwell Magnetic Field Formulation,” pp. 1-3, 2013.

[24] H. Kim and C. Lee, "Analysis of Eddy-Current Loss for Design of Small Active Magnetic Bearings With Solid Core and Rotor," vol. 40, no. 5, pp. 3293-3301, 2004.

[25] K. Lee and K. Park, "Analysis of an eddy-current brake considering finite radius and induced magnetic flux Analysis of an eddy-current brake considering finite radius and induced magnetic flux," vol. 5532, no. $2002,2014$.

[26] B. Lequesne, "Eddy-current machines with permanent magnets and solid rotors," IEEE Trans. Ind. Appl., vol. 33, no. 5, pp. 1289-1294, 1997. 


\section{BIOGRAPHIES OF AUTHORS}

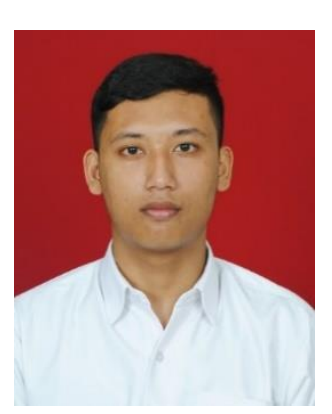

\section{Mufti Reza Aulia Putra S.T.,M.T.}

He was born in Boyolali, Central Jawa. He was completed his Bachelor's degree in Mechanical Engineering UNS in 2019 and a master's degree at the same university in 2020. In 2020 becomes student of doctoral degree in UNS.

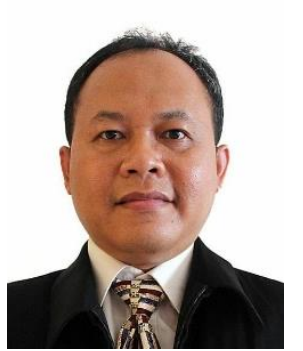

Prof. Ir. Muhammad Nizam S.T., M.T., Ph.D.

He was born in Surakarta, Central Java. He was completed his Bachelor's degree in Electrical Engineering UGM in 1993 and a master's degree at the same university in 2002. The Ph.D. degree was obtained from the Malaysian National University in 2008. Currently, he works in the fields of electric power systems, energy management, electric vehicles, and energy storage systems. Since 2011 he has been a Professor in the Department of Electrical Engineering, Faculty of Engineering, Universitas Sebelas Maret, Surakarta.

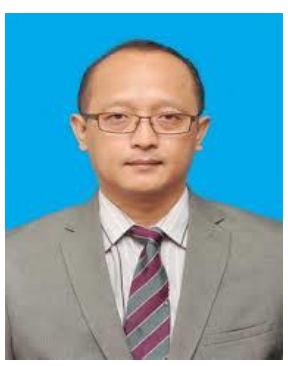

Dominicus Danardono Dwi Prija Tjahjana S.T., M.T., Ph.D.

He was born in Surakarta, Central Jawa. He was completed his Bachelor's degree in Mechanical Engineering UGM in 1995 and a master's degree at the same university in 2004. The Ph.D. degree was obtained from the Chonnam National University, South Korea in 2012. Currently, he works in the fields of renewable energy and mechanical system. He has been a Lecturer in the Department of Mechanical Engineering, Faculty of Engineering, Universitas Sebelas Maret, Surakarta.. 